\title{
SATISFAÇÃO COM OS ESTUDOS, CANSAÇO EMOCIONAL E ESTRATÉGIAS DE ENFRENTAMENTO EM ESTUDANTES UNIVERSITÁRIOS EM MANAUS - BRASIL
}

\author{
Ester Menezes dos Anjos \\ Faculdade Martha Falcão/Wyden (Manaus. Brasil) \\ anjosesther@gmail.com \\ Maria dos Reis Camelo \\ Manaus/ AM. Brasil
}

Fecha de Recepción: 4 Enero 2019

Fecha de Admisión: 30 Abril 2019

\section{RESUMO}

Este trabalho tem como objetivo analisar a relação entre satisfação com os estudos, estratégias de enfrentamento e exaustão emocional. Participantes da amostra foram 100 estudantes de duas Universidades Privadas na Cidade de Manaus, com idade entre 18 e 56 anos. Foram aplicadas a Escala de Fadiga Emocional (ECA) de Ramos, Manga e Moran (2005) como medida de estresse; esse questionário possui dois itens, um para avaliar a autoestima e outro para satisfação nos estudos. E COPE Breve de Carver (1997) avalia as 14 estratégias de enfrentamento. Os resultados obtidos confirmam que as estratégias mais utilizadas pelos participantes do estudo foram: Planejamento, Enfrentamento Ativo, Religião e Apoio Emocional; e que os alunos que apresentam uma alta autoestima têm maior satisfação com os estudos e menos fadiga emocional. Por outro lado, os estudantes que têm baixa autoestima relatam mais estresse e usam estratégias de enfrentamento mais desvalidas, com menor compacidade para resolver problemas.

Palavras chave: estratégias de enfrentamento; satisfação nos estudos; estrés acadêmico

\section{ABSTRACT}

Satisfaction with studies, emotional weakness and focusing strategies in university students in Manaus - Brazil. The aim of this work was to find the relationship between satisfaction with studies, coping strategies and emotional exhaustion. The participants were 100 economics students from a private university in the city of Manaus, between 18 and 56 years old. They were applied the Scale of Emotional Fatigue (ACE) of Ramos, Manga and Moran (2005) as a measure of stress; this questionnaire also has two items, one to assess self-esteem and another to satisfaction with the studies. And COPE Breve de Carver (1997) to evaluate the 14 coping strategies. The results inform that the strategies most used by the participants in the study were: Planning, Active Coping, Religion 


\section{SATISFAÇÃO COM OS ESTUDOS, CANSAÇO EMOCIONAL E ESTRATÉGIAS DE ENFRENTAMENTO EM ESTUDANTES UNIVERSITÁRIOS EM MANAUS - BRASIL}

and Emotional Support; that students with high self-esteem have greater satisfaction with studies, and less emotional fatigue. On the contrary, students who have low self-esteem report more stress and use more impoverished coping strategies and with less competence to solve problems.

Keywords: coping strategies; satisfaction of studies; academic stress

\section{INTRODUÇÃO}

Nos últimos anos, aconteceram mudanças significativas em todos os níveis da sociedade, que provocam inquietação e acelera o processo de transformaç̧ão no contexto social, essas mudanças tem propiciado um aumento no nível de responsabilidades e exigências para com os estudantes e educadores em todos os níveis de ensino e aprendizagem. Tem-se buscado atender as expectativas do mundo atual e mercado de trabalho, que procura profissionais qualificados, com a finalidade de estimulá-Ios a investir em sua própria educação. Com a nova configuração do trabalho, e a busca por uma maior qualificação que demonstre, por um lado, que se pode conduzir a uma situação de enriquecimento intelectual e motivação para o trabalho, por outro lado, isso pode causar estresse ou alimentar os fatores no ambiente de trabalho e na formação acadêmica, caso esses fatores perdurem, a Síndrome de burnout será atingida.

A Síndrome de burnout acontece no campo profissional e, é possível encontra-la também nos estudantes universitários, com a diferença de que eles produzem uma identificação de tensão emocional quando estão com ele. Tem-se discutido a natureza e a mensuração do esgotamento emocional e a causa nos estudos universitários foram percebidas. 0 interesse deste trabalho é a relação entre 0 estresse emocional de estudantes universitários e as estratégias de enfrentamento. Com a contribuição para a disseminação do conhecimento, através de ações e intervenções, bem como reflexões com todos os envolvidos no processo educativo. Elevando o nível de qualidade na educação, o profissional de psicologia poderá lidar com o processo da gênese da Síndrome de burnout.

Burnout não é um tema novo em Psicologia, mas é um assunto pouco explorado ou discutido nas instituições de ensino superior na cidade de Manaus. Isso será relevante para informar, prevenir e intervir na Síndrome de burnout? Como sintoma e principal componente de burnout, a fadiga emocional é a resposta mais proeminente aos estímulos estressores do ambiente ocupacional, sendo este a primeira etapa desse processo. 0 esgotamento emocional não é a única experiência alcançada, é também algo que causa uma mistura de reações de distanciamento emocional e cognitivo no trabalho de alguém, supostamente como uma maneira de lidar com a sobrecarga de esforços. A fadiga emocional e o sofrimento são uma resposta básica ao estresse e estão à mercê de seu caráter emocional, oferecendo uma perspectiva mais rica ao estudo do enfrentamento.

Da mesma forma que acontece com o burnout no campo profissional, é possível encontra-lo nos estudantes universitários, com a diferença de que eles produzem uma identificação de tensão emocional quando estão com ele. Tem-se discutido a natureza e a mensuração do esgotamento emocional e a causa dos estudos universitários foram percebidas. 0 interesse deste trabalho é a relação entre 0 estresse emocional de estudantes universitários e as estratégias de enfrentamento. Com a contribuição para a disseminação do conhecimento, através de ações e intervenções, bem como reflexões com todos os envolvidos no processo educativo. Elevando o nível de qualidade na educação, o profissional de psicologia poderá lidar com o processo da gênese da Síndrome de burnout.

Nos recursos de enfrentamento, tanto nos recursos pessoais, como nos recursos sociais, foram adicionados, aos recursos pessoais, além de personalidade, crenças, autoconceito, autoestima e gestão de outras emoções, que pertencem à esfera do intangível, que também influem nos bens materiais, de alguma forma e em alguns problemas, sejam também mediadores nas respostas ao estresse. 
As Estratégias de Enfrentamento são os as ações que fazemos para lidar com o estresse:

Planejamento: É um modo de enfrentar com os esforços que resolvem o problema, por meio de uma abordagem para a análise dos mesmos, para a busca planejada de soluções e para a implementação mais adequadas. As pessoas que usam o planejamento para enfrentar os problemas sentem-se mais realizadas profissionalmente em seu trabalho e nos estudos;

Apoio emocional: É um modo de confronto impulsionado pela emoção, quando um indivíduo conta seu problema para um amigo, seja um membro da família ou qualquer confidente com o objetivo de compartilhar as emoções que provocam esse conflito;

Busca por apoio social: De acordo com Lazarus e Folkman (1986) caracteriza-se pelos esforços que buscam a ajuda de outras pessoas quando o indivíduo não consegue lidar com situações estressantes.

Religião: De acordo com os dados coletados sugerem que o uso da religião como um estilo de enfrentamento pode ser utilizado por muitas pessoas. Como eles tendem a tratar isso como um estilo de enfrentamento, hoje nos deparamos com um dilema;

Reinterpretação Positiva: Transcreve os esforços para dar um significado à situação estressante, promovendo a partir do desenvolvimento pessoal. 0 que significa que a pessoa não vive o problema reclamando do que está acontecendo, mas procura o que pode ajudar a sair dele, quais vantagens positivas são o fato de estar nessa situação e como isso pode fortalecê-la ou ajudá-la a crescer e melhorar;

Aceitação: Aceitação da responsabilidade é uma resposta funcional do enfrentamento, de modo que a pessoa que aceita a realidade de uma situação estressante, parece tentar lidar com essa situação. A aceitação afeta dois aspectos do processo de enfrentamento. Uma é a aceitação de um fator estressante como verdadeiro, que é a consideração principal e 0 outro, a aceitação de uma ausência de estratégia de enfrentamento ativa relacionada ao exame secundário;

Negação: Muitas vezes é sugerido que a negação é útil, o que minimiza a angústia e a facilidade de enfrentamento. A negação só criará problemas adicionais, se o estres for ignorado. Ou seja, negar a realidade do evento, permite que o caso se torne mais grave, por isso é difícil enfrentá-lo, e isso precisa ser feito ao longo do tempo;

Humor: Carver entende que o humor é uma forma descontraída e divertida, inclusive quando são feitas piadas sobre isso. É um confronto que pretende atuar como amortecedor e minimizar 0 fator de estres e os efeitos do estresse;

Auto distração: ocorre quando há utilização de uma variedade de atividades e, quando empregada, pode distrair o indivíduo para pensar sobre o propósito no qual o estressor interfere. Inclui também atividades alternativas usadas para libertar a mente do problema. Deve-se notar que essa tática é mais diversa do que aquelas que estão em outras categorias de enfrentamento. Portanto, pode dizer-se que é útil para a categoria conceitual e auto distração é visto como a formação de "múltiplos critérios de desempenho" (Fishbein e Ajzen, 1974), pelo fato de ser o comportamento de uma classe de unidades;

Auto culpa: a escala de auto culpa foi introduzida por Carver na COPE breve, porque traz a análise dos resultados, o que acabou por ser um bom preditor para desajuste estresse. Para Brief COPE, o sentimento de culpa é entendido como uma atitude do indivíduo em atribuir responsabilidade, em determinar os efeitos negativos, do sentimento de culpa ao lidar com situações de estresse, lidar com críticas e recriminação;

Desconexão de Conduta: 0 esforço que é reduzido para lutar contra o fator estressor, inclui uma tentativa de abandonar a realização dos objetivos no qual o fator de estresse interfere. A restrição da ação reflete os fenômenos que também são identificados como impotência. Em teoria, a restri- 


\section{SATISFAÇÃO COM OS ESTUDOS, CANSAÇO EMOCIONAL E ESTRATÉGIAS DE ENFRENTAMENTO EM ESTUDANTES UNIVERSITÁRIOS EM MANAUS - BRASIL}

ção da ação ocorre com maior probabilidade quando se esperam os maus resultados do confronto;

Alívio emocional/liberação emocional: a tendência de se concentrar na angústia e na sensação de derrota; muitos tentam lidar e fazem frente a esses sentimentos (Scheff, 1987). Tal resposta pode ser funcional, às vezes, por exemplo, quando uma pessoa está em um período de luto e 0 utiliza para aceitar a perda de um ente querido e seguir em frente. No entanto, existem razões para suspeitar que o foco nessas emoções (especialmente durante um período prolongado) pode impedir 0 ajuste (Felton, Revenson e Hinrichsen, 1984);

Uso de substâncias: 0 último estilo de enfrentamento proposto pelo uso de substâncias como álcool e drogas, esta escala mede 0 estilo de enfrentamento que 0 indivíduo busca como escape de uma situação de estresse, mediante 0 uso de substâncias estranhas no organismo, perseguindo um estado de consciência alterada.

Nos estudos anteriores com enfoque no estresse e suas consequências nos estudantes universitários são relevantes. Uma das consequências do estresse nos estudantes universitários que se há estudado em diferentes populações e a síndrome de burnout, conceito proposto para explicar um processo de deterioramento físico e mental de profissionais que trabalham nas áreas de ensino, saúde, trabalho social e de serviços legais como de emergência Freudenberger, (1974) em Blanch, Aluja y Biscarri (2003). Ramos, Manga y Morán (2005) definem o cansaço emocional como resposta mais destacada aos estímulos estressante no ambiente ocupacional é a primeira etapa do processo da síndrome de burnout. Segundo Ramos et al. (2005) a dimensão do cansaço causa o desgaste emocional e representa a resposta básica do estresse.

Além, da relação com o estresse, há encontrado evidencia de que a burnout se associa a diferentes constructos, por exemplo, McCraine y Bandasma (1990) encontraram em uma amostra de médicos correlacionadas com escassa autoestima e ansiedade entre outras variáveis; e reporta associação com ansiedade e depressão (Ramos et al., 2005), também encontraram correlação significativa entre cansaço emocional e baixa autoestima.

Em um estudo de González e Landero, com uma amostra 506 estudantes de psicologia, 365 da universidade pública e 141 de uma universidade privada, ambas no norte do México sobre a correlação do cansaço emocional com autoestima, as correlações no foram significativas. Outros resultados si confirmam os achados de McCraine e Bandasma (1990) cujos estudos são somente um exemplo de variáveis com que se há associado com o burnout. Nos casos de estudantes universitários Ramos et al. (2005) reportaram uma correlação negativa e alta entre cansaço emocional e autoestima.

Martinez, Marques, Salanova e Lopes da Silva, (2002) e Ramos et al. (2005) tem demonstrado que existe burnout nos estudantes universitários e que se apresenta em alunos dos últimos períodos de formação da carreira, assim, em estudantes de pós-graduação, sendo o cansaço emocional a maneira em que se manifesta, visto que as outras dimensões características do burnout - despersonalização e falta de realização pessoal, são praticamente inexistente nos estudantes.

Este trabalho tem como objetivo analisar a relação entre satisfação com os estudos, estratégias de enfrentamento e exaustão emocional.

\section{MÉTODO}

\section{Instrumentos de Medida}

Esta investigação tem como base os resultados mensurados através de questionários aplicados a alunos de ensino superior na cidade de Manaus- Amazonas (Brasil), o que está correlacionado com os resultados de uma investigação sobre a Escala de Cansaço Emocional (ECE) para estudan- 
tes universitários: Propriedades Psicométricas em uma amostra do México; realizado por Mônica Tereza Gonzalez Ramírez e René Landero Hernández na Universidade Autônoma Novo Leon (México), dezembro de 2007; destaca que os estudantes universitários tem sido o centro de muitas investigações pela facilidade de envolvê-los como participantes; acrescenta ainda que nos casos mais importantes os investigadores se ocupam das situações particulares em catalogá-los. Entre as situações específicas que geram o estresse em universitários, os autores da pesquisa mencionam que 0 cansaço emocional ocorre nos estudantes, devido à preocupação com o desempenho na universidade; o processo de adaptação ao ambiente universitário e as exigências em relação aos seus estudos e ao mesmo tempo se preocupam com o futuro.

Escala de Cansaço Emocional (ECE) - Utilizou-se a Escala de Cansaço Emocional (ECE) de Ramos, Manga e Morán (2005) que consta de 10 itens que medem cansaço emocional. Os itens são pontuados de 1 a 5 em uma escala tipo Likert. Com respostas: 1 corresponde muito poucas vezes; 2 poucas vezes; 3 algumas vezes; 4 com freqüência e 5 sempre, considerando os 12 últimos meses do período estudantil. A pontuação obtida na ECE oscila entre 10 a 50 pontos. 0 item 11 mede a satisfação com os estudos e 12 a auto-estima. A Escala de Cansaço Emocional foi traduzida do idioma Espanhol para o Português e revisado pelos autores desta investigação.

Questionário COPE - Breve de Carver - Adaptada por Pais Ribeiro e Rodrigues, (2004) do original Brief COPE de Carver (1997) avaliou os 14 estilos de enfrentamento nos estudantes de Ensino Superior na cidade de Manaus (Brasil). Os estilos de enfrentamento: Enfrentamento Ativo, Planificação, Apoio emocional, Apoio instrumental, Religião, Reinterpretação positiva, Aceitação, Negação, Humor, Autodistração, Auto-culpa, Desconexão conductual,Desafogo emocional e Uso de substâncias. Em escala tipo Likert que se pontuam de $0=$ nunca faço isto; $1=$ faço um pouco isto; 2 = faço bastante isto; e $3=$ faço sempre isto; onde se avaliam 14 modos de estratégias que as pessoas podem utilizar para enfrentar os problemas que the causam o estresse; com quatro possíveis respostas intermediárias que avaliam 0 apoio emocional e apoio social. Todos os itens são positivos por maior pontuação em cada modo de enfrentamento maior a utilização dessa estratégia.

\section{Desenho}

Efetuamos uma investigação quantitativa e descritiva, através de questionários de auto-observação com método correlacional-comparativa e estudo transversal. A metodoloogia utilizada foi a aplicação de Escala Emocional Ramos, Manga y Morán (2005), com variaveis de Cansanço Emocional, Satistação com os Estudos, a Autoestima e os estilos de Enfrentamento. No Questionario de Enfrentamento COPE Breve de Carver (1997) avalia 14 estilos de enfrentamento entre os estudantes de educação superior superior no Amazonas - Brasil, que tem como objetivo identificar os fatores determinantes da satisfação dos estudantes universitários no Amazonas e quais são as estratégias de enfrentamento de estresse utilizadas pelos alunos e verificar a relação entre 0 esgotamento emocional, a satisfação com os estudos e autoestima.

Os questionários foram aplicados no contexto da sala de aula, pelo diretor/Coordenadores dos Cursos da Faculdade, orientado pelos autores desta investigação.

Foram empregadas análises de correlação, multivariante e provas t de diferenças de médias.

\section{Amostra}

0 Universo desta amostra foi formado por 02 Instituições de Ensino Superior Privada, localizadas na cidade de Manaus - Amazonas - Brasil. Composta de 680 alunos do Curso de Administração, 320 do Curso de Contabilidade e 250 do Curso de Serviço Social.

A- Amostra - A amostra é constituída de 100 estudantes composta por homnes e mulheres que 
cursam o Ensino Superior de uma Instituição de Ensino Superior Privada situada na cidade de Manaus - Amazonas - Brasil. Sendo distribuida em 50 estudantes do curso de Serviço Social; 34 estudantes do curso de Administração es 16 estudantes do curso de Contabilidade, que estudam pelo periodo da noturno. A média de idade foi de 30 anos; sendo 0 aluno mais joven com 18 anos e a maior idade de 56 anos com participação de $76 \%$ do sexo feminino e somente $24 \%$ do sexo masculino.

B - Variáveis estudadas

Variáveis demográficas: Gênero. A idade é uma das variáveis que foi estudada na intenção de verificar sua correlação com a Escala de Cansaço Emocional em estudantes de Ensino Superior.

Variáveis psicológicas: Denomina-se variavéis psicológicas relativas aos traços estudados da personalidade. A Escala de Cansaço Emocional mede as seguintes variaveis psicológicas: 0 cansaço emocional, a satisfação com os estudos e a auto-estima.

Os estilos de enfrentamento estudados são: Enfrentamento Ativo, Planejamento, Apoio Emocional, Apoio Instrumental, Religião, Reinterpretação Positiva, Aceitacão, Negação, Humor, Auto-distração, Desconexção, Conduta, Desafogo Emocional.

\section{RESULTADOS}

\section{Estratégias de enfretamento mais utilizadas pelos universitários estudados}

De acordo com tabela 1, constatou-se que os Estudantes universitários da amostra, utilizam mais as estratégias ativas de enfrentamento quando enfrentam os problemas que the causam estresse como: Planificação ( $\mu=4,44 ; \mathrm{DT}=1,27)$ e Enfrentamento ativo $(\mu=4,41 ; \mathrm{DT}=1,14)$, também utilizam com alta frequência 0 apoio da Religião $(\mu=4,15$; $D T=1,70)$ e Reinterpretação positiva $(\mu=3,82 ; \mathrm{DT}=1,49)$. As estratégias menos utilizadas pelos estudantes foram: 0 desafogo $(\mu=2,40$; $\mathrm{DT}=1,44)$; a auto culpa $(\mu=2,22$; $\mathrm{DT}=1,27)$; humor $(\mu=2,11 ; \mathrm{DT}=1,61)$; desconexão conduta $(\mu=$ 1,74; DT=1,39); negação ( $\mu=1,63$; DT=1,53); e pouco uso de substâncias $(\mu=, 21$; DT= ,701).

Tabela 1. Estadísticos descriptivos de las 14 escalas del Brief COPE.

\begin{tabular}{l|cccc} 
& Mínimo & Máximo & Media & Desvio Tipico (DT) \\
\hline Planificação & 1 & 6 & 4,44 & 1,274 \\
Enfrentamento Ativo & 2 & 6 & 4,41 & 1,138 \\
Religião & 0 & 6 & 4,15 & 1,696 \\
Reinterpretação Positiva & 0 & 6 & 3,82 & 1,493 \\
Distração & 0 & 6 & 3,27 & 1,543 \\
Apoio Instrumental & 0 & 6 & 3,23 & 1,448 \\
Aceitação Responsabilidade & 0 & 6 & 3,20 & 1,407 \\
Apoio Emocional & 0 & 6 & 3,13 & 1,548 \\
Desafogo & 0 & 6 & 2,40 & 1,443 \\
Auto culpa & 0 & 6 & 2,22 & 1,276 \\
Humor & 0 & 6 & 2,11 & 1,614 \\
Desconexão de Conduta & 0 & 5 & 1,74 & 1,397 \\
Negação & 0 & 5 & 1,63 & 1,535 \\
Uso de substancias & 0 & 4 &, 21 &, 701 \\
\hline
\end{tabular}


Tabela 2. Correlação entre o cansaço emocional e estratégias de afrontamento- Elaborado pelas autoras

Estratégias de Enfrentamento Cansaço Emocional

\begin{tabular}{lc}
\hline Enfrentamento Ativo &, 017 \\
\hline Planificação &, 870 \\
\hline Apoio Emocional &, 029 \\
&, 024 \\
\hline Apoio instrumental. &, 810 \\
\hline Religião &, 174 \\
&, 083 \\
\hline Reinterpretação. Positiva &, $209\left(^{*}\right)$ \\
&, 037 \\
\hline Aceitação &, 118 \\
&, 244 \\
\hline Negação &, 081 \\
&, 425 \\
\hline Humor &, $272\left(^{* *}\right)$ \\
&, 006 \\
\hline Distração &,- 003 \\
&, 980 \\
\hline Auto culpa &, $238\left(^{*}\right)$ \\
\hline Desconexão &, 017 \\
\hline Desafogo &, $287\left(^{* *}\right)$ \\
\hline Uso substancias Total &, 004 \\
\hline &, 071 \\
&, 485 \\
\hline &, 151 \\
&, 134 \\
\hline &,- 102 \\
&, 310 \\
\hline
\end{tabular}

$\mathrm{Na}$ análise dos dados da tabela 2, verificamos 14 estilos de enfrentamento que correlacionam com o cansaço emocional nos estudantes universitários. Os quatro estilos de enfrentamento que correlacionam com 0 cansaço emocional de forma positiva; são: auto-culpa ( $r=, 287 ; p=, 004)$, a negação $(r=, 272 ; p=, 006)$, a religião $(r=, 209 ; p=, 037)$; e Distração $(r=, 238, p=017)$. Em relação aos resultados constatamos que os indivíduos mais cansados emocionalmente são os que mais empregam a auto-culpa; a negação, a religião e a Distração como estratégias para enfrentar o cansaço emocional. Concluímos que quanto maior uso destes estilos maior será o cansaço emocional nos estudantes.

Relação entre o cansaço emocional, a autoestima e a satisfação com os estudos. 
Tabela 3. Relação entre o cansaço emocional, a auto-estima e a satisfação com os estudos

\begin{tabular}{l|cc} 
& Satisfação com os estudos & Autoestima \\
\hline Cansanço Emocional & $-0,159$ & $-0,122$ \\
& 0,155 & 0,273 \\
Satisfação com os estudos & 1 & $0,482(* *)$ \\
& &, 000 \\
\hline
\end{tabular}

** A correlação é significativa ao nível 0,01 (bilateral).

Verificamos que os estudantes com autoestima elevada alcançam maior satisfação com os estudos, e que são capazes de reagir às situações de estresse de modo mais saudável, e ETA autoestima atua como um amortecedor dos efeitos negativos do estresse. Porém as pessoas que tem uma baixa autoestima tendem a ser mais vulneráveis em situações estressantes e desenvolvem estratégias de enfrentamento, mais desvalida e com uma menor competência para superar o estresse.

\section{Diferenças do gênero entre as variáveis estudadas}

Tabela 4. Provas das amostras independentes entre as variáveis estudadas

\begin{tabular}{ll|ccccc} 
& Sexo & $\mathrm{N}$ & Media & $\begin{array}{c}\text { Desvio } \\
\text { típico. }\end{array}$ & $\mathrm{T}$ & Sig.(p) \\
\hline Cansaço Emocional & Homem & 24 & 21,65 & 5,556 & - &, 000 \\
& Mulher & 76 & 29,01 & 5,839 & 5,355 & \\
Satisfação com os & Homem & 33 & 4,20 &, 775 &,- 279 &, 781 \\
estudos & Mulher & 67 & 4,27 &, 880 & & \\
Autoestima & Homem & 33 & 4,00 &, 756 &, 919 &, 361 \\
& Mulher & 67 & 3,75 & 1,005 & &
\end{tabular}

Na Tabela 4, se observa que nos estudantes de ensino superior, o gênero masculino revela menor cansaço emocional obtendo ( $\mu=21,65$; DT= 5,55); e que as mulheres revelam maior cansaço emocional $(\mu=29,01 ; \mathrm{DT}=5,83)$. Esta diferença é estatisticamente significativa $(t=-5,355, p=$ ,000). Quanto à satisfação com os estudos constatou-se que tanto os homens quanto as mulheres apresentam equilíbrio (homens: $\mu=29,01$; DT $=5,56)$; mulheres: $(\mu=29,01$; DT $=5,83$ ). Com relação à autoestima os estudantes de ensino superior do gênero masculino obtêm maior autoestima $(\mu=4,0 ; \mathrm{DT}=, 756)$ e em relação ao sexo feminino demonstram autoestima menor ( $\mu=3,7$; DT= 1,965); embora a diferença não seja muito significativa.

\section{Diferencias de gênero em afrontamento}

De acordo com a tabela 5, pode-se observar na prova t das amostras independentes quanto os resultados obtidos neste estudo, em relação ao critério de gênero apresenta diferenças entre homens e mulheres. 
Tabela 5. Provas das amostras independentes

\begin{tabular}{|c|c|c|c|c|c|c|}
\hline & Sexo & $\mathrm{N}$ & Media & Des. típ. & $\mathrm{t}$ & Sig \\
\hline \multirow[t]{2}{*}{ Enfrent. Ativo } & Homem & 24 & 4,57 & 1,080 & 678 & ,499 \\
\hline & Mulher & 76 & 4,38 & 1,154 & & \\
\hline \multirow[t]{2}{*}{ Planificacão } & Homem & 24 & 4,70 & 1,295 & 1,038 & ,302 \\
\hline & Mulher & 76 & 4,38 & 1,265 & & \\
\hline \multirow[t]{2}{*}{ Apoio emocion. } & Homem & 24 & 3,09 & 1,411 &,- 191 & 849 \\
\hline & Mulher & 76 & 3,16 & 1,600 & & \\
\hline \multirow[t]{2}{*}{ Apoio instrum. } & Homem & 24 & 3,26 & 1,356 & ,032 & ,975 \\
\hline & Mulher & 76 & 3,25 & 1,471 & & \\
\hline \multirow[t]{2}{*}{ Religião } & Homem & 24 & 3,26 & 1,685 & $-3,074$ & 003 \\
\hline & Mulher & 76 & 4,45 & 1,603 & & \\
\hline \multirow[t]{2}{*}{ Reinte. Positiva } & Homem & 24 & 3,61 & 1,588 &,- 843 & ,401 \\
\hline & Mulher & 76 & 3,91 & 1,462 & & \\
\hline \multirow[t]{2}{*}{ Aceitação } & Homem & 24 & 2,61 & 1,406 & $-2,349$ & 021 \\
\hline & Mulher & 76 & 3,38 & 1,376 & & \\
\hline \multirow[t]{2}{*}{ Negação } & Homem & 24 & 1,35 & 1,496 & $-1,066$ & 289 \\
\hline & Mulher & 76 & 1,74 & 1,544 & & \\
\hline \multirow[t]{2}{*}{ Humor } & Homem & 23 & 2,17 & 1,850 & 177 & 860 \\
\hline & Mulher & 76 & 2,11 & 1,554 & & \\
\hline \multirow[t]{2}{*}{ Distração } & Homem & 24 & 2,65 & 1,465 & $-2,338$ & 021 \\
\hline & Mulher & 76 & 3,49 & 1,510 & & \\
\hline \multirow[t]{2}{*}{ A-culpa } & Homem & 24 & 1,83 & 1,435 & $-1,761$ & 081 \\
\hline & Mulher & 76 & 2,36 & 1,208 & & \\
\hline \multirow[t]{2}{*}{ Desconexão } & Homem & 24 & ,96 & 1,022 & $-3,233$ & ,002 \\
\hline & Mulher & 76 & 1,99 & 1,419 & & \\
\hline \multirow[t]{2}{*}{ Desafogo } & Homem & 24 & 2,00 & 1,348 & $-1,639$ & , 105 \\
\hline & Mulher & 76 & 2,55 & 1,437 & & \\
\hline \multirow[t]{2}{*}{ Uso substâncias } & Homem & 24 &, 52 & ,994 & 2,470 &, 015 \\
\hline & Mulher & 76 &, 12 &, 565 & & \\
\hline
\end{tabular}

As mulheres utilizam mais a estratégia de enfrentamento na Religião obtendo $(\mu=4,45)$; em relação aos homens que apresentam $(\mu=3,26)$. Quanto à estratégia de Aceitação as mulheres revelam maior capacidade de aceitação do problema obtendo $(\mu=3,38)$; em relação aos homens que obtém menor $(\mu=2,61)$; em relação à Distração as mulheres apresentam maior utilização, obtendo ( $\mu=$ $3,49)$; em relação aos homens que atingiram menor pontuação $(\mu=2,65)$. Quanto ao uso de substâncias os estudantes do sexo masculino fazem quatro vezes mais o uso de substâncias em relação ao sexo oposto $(\mu=, 52)$; as mulheres fazem menor Uso de substâncias em relação aos homens; estas obtiveram nesta amostra $(\mu=, 12)$. Dentre as estratégias pesquisadas nesta amostra foram as que apresentaram diferenças significativas. Constata-se que, as mulheres utilizam com menor frequência as estratégias de enfrentamento quanto ao uso das substâncias.

Esta investigação teve como objetivo analisar a relação entre satisfação com os estudos, estratégias de enfrentamento do estresse e exaustão emocional, com a identificação de quais são as estratégias mais utilizadas pelos estudantes universitários para 0 enfrentamento do estresse. $\mathrm{Na}$ 


\section{SATISFAÇÃO COM OS ESTUDOS, CANSAÇO EMOCIONAL E ESTRATÉGIAS DE ENFRENTAMENTO EM ESTUDANTES UNIVERSITÁRIOS EM MANAUS - BRASIL}

amostra investigada verificou-se que os estudantes universitários brasileiros utilizam com maior frequência as estratégias de enfrentamento: Planificação, Enfrentamento Ativo, Religião e Reinterpretação Positiva.

Planificação, para enfrentar os problemas, para lidar com os problemas que lhes causam estresse, assim, como uma boa autoestima. As variáveis da personalidade que predizem o maior uso do modo planificação são a responsabilidade e alta abertura do indivíduo Enfrentamento ativo, também utilizam com alta frequência 0 apoio da Religião e a Reinterpretação positiva;

Enfrentamento Ativo para eliminar ou reduzir os efeitos do estresse. 0 enfrentamento ativo tem iniciação direta, o aumento do esforço e o desejo de executar, o indivíduo se adapta de forma gradual frente 0 estresse;

Religião empregado pelos estudantes, a religião serve como fonte de apoio emocional, como um veículo para a interpretação positiva e crescimento;

Reinterpretação Positiva, denominada reavaliação positiva como um tipo enfrentamento enfocado na emoção, a interpretação desta tendência não está limitada a angústia. Interpretar uma situação estressante em termos positivos deve leva a pessoa de forma intrínseca a continuar acionando 0 enfrentamento ativo.

Verificou-se também que as estratégias utilizadas com menor frequência são: Negação, Desafogo, Desconexão de Conduta, Auto culpa, Humor e com pouquíssima utilização do uso de substancias, para lidar com 0 estresse diário da vida acadêmica; de forma geral os alunos de universidades privadas, trabalham durante 0 dia e após uma jornada de trabalho de 8 horas, estudam à noite por mais 4 horas, totalizando 12 horas diárias de atividades.

Desafogo das emoções com a tendência de centra-se na angústia o transtorna e faz experimentar e tentar resolver esses sentimentos. Tal resposta pode ser funcional ás vezes, quando uma pessoa usa por um período de luto para acomodar a perda de um ente querido e seguir adiante;

Auto culpa, evidencia-se pelo seu significado. A auto culpa é uma atitude que os estudantes utilizam para um mau ajuste ao estresse. Os estudantes atribuem muitas responsabilidades de determinados feitos negativos;

Humor, mostra uma pequena utilização nos estudantes pesquisados, entende como um modo de enfrentamento que atua como um amortecedor e minimiza 0 agente estressor e os efeitos do estresse.

No grupo investigado de 100 estudantes universitários, verificou-se que em relação a estratégia referente ao humor os estudantes fazem pouco uso do estado de humor para 0 enfrentamento em relação ao cansaço emocional; e pouco uso de substâncias como álcool e as drogas. Ou seja, Assim, como a utilização do estilo da desconexão de conduta, recorrendo a variadas atividades para distrair a pessoa em razão do estresse, é um estilo de enfretamento empregado pelos estudantes mais cansados emocionalmente. A auto culpa entendida como atribuição de responsabilidade de fatos negativos de exaustão nos estudantes. Entretanto, vale ressaltar que os estudantes de Ensino Superior labutam para manter seus estudos; trabalham durante 0 dia e estudam a noite enfrentando carga horária de 12 horas diárias de atividades.

Com relação ao grau de cansaço emocional nos universitários estudados foi identificado que os estudantes apresentam significativo cansaço emocional; baixa satisfação com seus estudos e baixa autoestima. Conclui-se que os indivíduos que estão mais cansados emocionalmente, em consequência da sua ocupação laboral e de estudantes, são os que empregam a negação com o propósito de esquecer os problemas, utilizam o estilo da negação em detrimento da realidade, ou seja, vivendo como se nada estivesse ocorrendo; esta estratégia da negação produz mais esgotamento nos estudantes. São vários os tipos sociais de negação entre eles o escapismo, adiamento de com- 
promissos, recusa de enfrentamento desagradáveis, criação de doenças imagináveis para fugir de responsabilidades, subterfúgios. A negação pode ir a um ponto de irracionalidade, por exemplo: 0 estudante deixa de comparecer à prova, com medo de ir mal, mesmo sabendo que sua ausência implicará em nota zero. 0 negador mente para si mesmo, prometendo que da próxima vez será diferente.

Sobre a correlação entre o cansaço emocional e as estratégias de enfrentamento utilizadas, os estudantes utilizam significativamente à estratégia de enfrentamento da auto culpa, a negação, a religião e baixo uso de substâncias. Ou seja, para enfrentar o cansaço emocional causado pela vida acadêmica e outras variáveis do seu cotidiano, o processo de culpar a si mesmo, é compreendida como a atitude do sujeito por atribuir-se de responsabilidade e efeito negativo; apoiar-se na religião como fonte de apoio emocional como um veículo para a interpretação positiva e crescimento, como uma tática de enfrentamento ativo com um estressor.

Sobre as diferenças de gênero nas variáveis estudadas, o aspecto importante neste grupo estudado o sexo masculino revelam menor cansaço emocional em relação ao sexo feminino; ou seja, embora, os homens apresentem menor cansaço emocional revelam uma alta estima mais elevada que as mulheres e estão menos satisfeitos com seus estudos. Entretanto, nesta pesquisa as mulheres revelam maior cansaço emocional e estão mais satisfeitas com seus estudos em relação aos homens, mesmo apresentando uma autoestima mais baixa em relação aos homens.

As características sócias demográficas da presente investigação confirmam o perfil dos estudantes universitários brasileiros principalmente na região norte do Brasil, no Amazonas/Manaus, caracteriza com maior predominância, do gênero feminino com $76 \%$ em relação menor participação dos homens $24 \%$, com a média de idade de 30 anos, a pessoa de maior idade 56 anos e a pessoa mais jovem com 18 anos. Em função das dificuldades de acesso do jovem à universidade brasileira, o que retarda seu ingresso a uma instituição de ensino superior, na sua grande maioria procuram umas instituições de ensino privado, em razão das dificuldades para se inserir em uma universidade pública.

\section{CONCLUSÃO E SUGESTÕES}

Com esta investigação constatamos que entre os fatores estressores, mais frequentes estão, por um lado, as condições estruturais da sua condição acadêmica, tais como horários, aulas e traslados, realização dos exames e à espera da qualificação; por outro lado, a incerteza quanto ao futuro profissional Peñacoba e Moreno (1999). Entretanto, alguns professores contribuem com que se intensifiquem as preocupações, quando poderiam contribuir e facilitar a adaptação dos estudantes às condições universitárias e de ensinar-Ihes um adequado manejo ao estresse gerado por estas condições.

A investigação comprovou que as estratégias mais utilizadas pelos estudantes de Ensino Superior no Amazonas são: Planificação, Enfrentamento Ativo, Planejamento, Apoio Emocional, Apoio Instrumental, Religião, Reinterpretação Positiva, Aceitação, Negação, Humor, Auto-distração, Desconexão, Conduta, Desafogo Emocional, nas situações, quando se enfrenta os problemas que causam estresse e os estudantes com alta autoestima gozam uma maior satisfação com os estudos, são capazes de reagir as situações de estresse com mais saúde, uma autoestima alta atua como amortizador dos efeitos negativos do estresse, no entanto, os estudantes que tem baixa estima tendem a ser mais vulneráveis em situações de estres e desenvolver estratégias de enfrentamento e com menor competência.

Nos objetivos delineados para este estudo se cumpre satisfatoriamente. Considerando que os estudos sobre a Síndrome de burnout devem continuar e ampliar-se a investigações sobre a eficá- 
cia de programas de prevenção e tratamento, contar com apoio das instituições, já que as universidades estão preocupadas em melhorar o nível de qualidade do ensino e isto implica em considerar todas as variáveis relacionadas no processo de ensino e aprendizagem e o cansaço emocional está relacionado com as expectativas de êxito para finalizar os estudos.

\section{REFERENCIAS}

Ajzen, I., Fishbein. M. (1974). Factoring influencing intention and the intention behavior relation. Human Relation, 27, 1-15.

Blanch, A., Aluja. A. e Biscarri, J. (2003). burnout syndrome and coping strategies: a structural relations model. Psychology in Spain, 7 (1), 46-55.

Carver, C. S. (1997). You want to measure coping but your protocol's too long: Consider the Brief COPE. International Journal of Behavioral Medicine, 4, 92-100.

Felton, B. J.; Revenson, T. A. e Hinrichsen, G. A. (1984). Stress and coping in the explanation of psychological adjustment among chronically ill adults. Social Science e Medicine, 18, 889-898.

Freudenberger, H. R. G. (1974). Burnout: the high achievement. New York: Doubleday.

Gil M. P. y Peiró, J. M. (1997). Desgaste psíquico en el trabajo. El Síndrome de quemarse. Madrid: Síntesis.

Lazarus, R. S. y Folkman, S. (1986). Stress, appraisal, and coping. New York: Spronger.

Maslach, C. (2003). Job burnout: New directions in research and intervention. Current Directions in Psychological Science, 12, 189-192.

McCraene, R. R. Bandasma (1990). Controlling neuroticism in the measurement of stress. Stress Medicine, 6, 237-241.

Peñacoba, C. Moreno, B. (1999). La escala de estresores universitarios (EEU). Una propuesta para la avaliación del estrés en grupos de poblaciones especificas. Ansiedad y Estrés, 5 (1), 61-78.

Ramos, F. y Buendía, J. (2005). El Síndrome de burnout: concepto. Evaluación y tratamiento. En J. Buendía y F. Ramos (Coord.), Empleo, estrés y salud, (pp 33-57). Madrid: Pirámide.

Ramos, F., Manga, D. e Morán, C. (2005). Escala de cansancio emocional para estudiantes universitarios. Propiedades psicométricas e asociación con medidas de personalidad e salud psicológica. Comunicación al 6ํㅜㄹ Congreso Virtual de Psiquiatría. Interpsiquis. http://www.psiquiatria.com/interpsiquis 2005/.

Scheff, T. J. (1987). Bloody Devenge. Oxford: Westview Press. 